\title{
High Selectivity UWB Bandpass Filter with a Wide Notched-Band
}

\author{
Seyyed Jamal Borhani ${ }^{1}$, M. Amin Honarvar ${ }^{1}$, Bal S.Virdee ${ }^{2}$
}

${ }^{1}$ Department of Electrical Engineering, Najafabad Branch, Islamic Azad University, Najafabad, Iran;

${ }^{2}$ B. S. Virdee is with Center for Communications Technology, London Metropolitan University, UK.

\begin{abstract}
This paper presents a compact ultra-wideband (UWB) bandpass filter with sharp selectivity, wide notched-band, wide out-of-band rejection, and approximately flat group delay. The proposed filter structure comprises of a U-shaped open-circuited line that is inter-digitally coupled to the input/output feed-lines using high impedance lines. The structure generates multiple resonant modes across the UWB span between 3.1 and $10.6 \mathrm{GHz}$, however high coupling between the feed-lines and the U-shaped structure transforms the discrete resonant modes into an UWB bandpass filter. Coupling is enhanced by inserting dielectric slots in the groundplane immediately under the coupling-lines. A wide notched-band is implemented by introducing asymmetry in the coupled lines. This was achieved by making one of the coupling lines longer by folding it and extending the line to partially couple with U-shaped structure. The length of the extended coupled line and the position of the folded section determine the center frequency of the notch-band and its $3-\mathrm{dB}$ bandwidth. The notch was designed to be centered at $5.5 \mathrm{GHz}$ with appropriate $3-\mathrm{dB}$ bandwidth to blocking interference from WLAN signals. The selectivity of the filter was enhanced by loading the U-shaped structure with a T-shaped open-circuited stub to generate two additional resonant modes in the filter's passband and two transmission zeros that were strategically located at the upper and lower cut-off frequencies of the filter. The design was fabricated and its performance verified. The proposed filter has dimensions of $9.4 \mathrm{~mm} \times 9.9 \mathrm{~mm}$.
\end{abstract}

Keywords: Ultra-wideband, bandpass filter, multiple-mode resonator, notched-band

\section{Introduction}

UWB communications systems need to operate across a very large transmission bandwidth, namely 3.1 to $10.6 \mathrm{GHz}$ [1], and filters play an important role in determining the systems' overall performance. Such systems require UWB bandpass filters (BPF) to have a lower pass-band insertionloss, high selectivity, higher out-of-band rejection, and flat group-delay. Hence, the design of such filters is a non-trivial task which presents a challenge for design engineers [2]-[21]. Multimode resonators (MMR) have been shown to present a viable solution of designing UWB BPFs, and various MMR configurations have been reported to date [2]-[7]. Another essential requirement of UWB BPFs is to eliminate undesired interference from coexisting wireless communication systems such as WiMAX at $3.5 \mathrm{GHz}$, WLAN at $5.5 \mathrm{GHz}$, RFID at $6.8 \mathrm{GHz}$, and satellite communication at $8 \mathrm{GHz}$. This necessitates the use of single or multiple notch-band filters. Various methods and configurations have been reported that incorporate the notch-band functionality within the UWB BPF to save space [8]-[21]. In [8] and [9] notched-band at $5.6 \mathrm{GHz}$ and $6.6 \mathrm{GHz}$, respectively, were realized by using asymmetric coupling lines but the selectivity of these filters is poor and its performance fall short of the UWB frequency range. In [10], quarter-wavelength spur lines were embedded in the resonator to create a notched-band centered at $5.69 \mathrm{GHz}$ with a 3-dB notch bandwidth of $18 \%$. In [11] a spiral slot is used to generate a notched-band around $5.5 \mathrm{GHz}$. A ring resonator with two stepped-impedance stubs is used in [12] to produce a notched band. Although this UWB filter had good selectivity performance however it is relatively large in size. In [15] a narrow slot embedded within the resonator is shown to produce a bandstop but its selectivity and size needs to be improved for practical applications. A radial stub loaded resonator in [16] is shown to produce a notched band at $8.0 \mathrm{GHz}$ but its upper stopband falls short of the UWB frequency range. Lately, quadruple-mode notched-band UWB BPFs have been reported in [17][18] that have a wide upper stopband. In [18], the notched-band is achieved around $5.6 \mathrm{GHz}$ using short-circuited stub which in practice introduces a level of complexity. Recent works in [19]-[21] report UWB BPFs with dual or triple notched-bands. However, these filters suffer from poor selectivity. Although extensive investigation has been conducted on UWB BPFs there is still a requirement for such filters that meet stringent requirements of sharp rejection skirts, wide upper stopband, notched-band functionality, and compact size. 
In this paper, a compact notched-band UWB BPF structure is presented that exhibits high selectivity, approximately flat group delay and high out-of-band rejection over a wide frequency range. The triple mode resonant structure is realized using a U-shaped open-circuit resonator of uniform characteristic impedance which is tightly coupled with the input/output feed-lines using interdigital coupled lines. Notched-band is implemented by introducing asymmetry in the inter-digital coupled lines. The notch was centered at around $5.5 \mathrm{GHz}$ to blocking interference from WLAN signals. The selectivity of the filter was enhanced by adding two additional resonant modes in the filter's passband and two transmission zeros near its upper and lower cut-off frequencies. This was achieved by loading the U-shaped resonator with T-shaped open-circuited stub. Measured results confirm the compact filter exhibits a sharp roll-off, high selectivity and high out-of-band rejection over a wide frequency span with an almost flat group delay. The filters performance includes a notched-band between 5.14 and $5.84 \mathrm{GHz}$ of a high rejection level.

\section{Notched-Band UWB Bandpass Filter}

\section{a) UWB Filter Topology}

Fig. 1(a) shows the initial configuration of the proposed UWB bandpass filter that comprises of input and output feed-lines that are directly coupled to a U-shaped open-circuited transmission-line of uniform characteristic impedance using high impedance inter-digital coupled lines. The U-shaped structure in combination with the high impedance coupling lines behaves analogously to a multimode resonator. The characteristic impedance of the MMR structure is higher than the feed-lines, which contributes to size reduction. Inter-digital coupled lines are used to provide tight coupling between the MMR and $50 \Omega$ input/output feed-lines. The lengths of the high-impedance coupling lines and the Ushaped low-impedance line are $\lambda_{g} / 4$ and $\lambda_{g} / 2$, respectively, where $\lambda_{g}$ is guided-wavelength with respect to center frequency $f_{o}=6.85 \mathrm{GHz}$. The inter-digital coupled lines can be modeled in terms of a J-inverter network.

Since the MMR structure is symmetric, the even- and -odd mode technique can be applied to analyze it. The even- and odd-mode equivalent circuits of the proposed MMR are shown in Fig. 1(b) and (c), respectively. From the following resonant conditions: $Y_{\text {in,even }}=0$ and $Y_{i n, o d d}=0$, the evenand odd-resonant frequencies can be determined using:

$$
\begin{aligned}
& Y_{1}\left(\tan \theta_{1}+\tan \theta_{2}\right)+Y_{h} \tan \theta_{h}=0 \\
& Y_{1}-Y_{1} \tan \theta_{1} \tan \theta_{2}-Y_{h} \tan \theta_{h} \tan \theta_{2}=0
\end{aligned}
$$

Fig. 2 shows the three distinct resonate modes $\left(f_{m 1-o d d}, f_{m 2-e v e n}\right.$, and $\left.f_{m 3-o d d}\right)$ excited by the structure under weak coupling $\left(L_{C}=1 \mathrm{~mm}\right)$ which are equally distributed within the desired band, i.e. $3.1 \sim 10.6 \mathrm{GHz}$. However, by increasing the degree of coupling $\left(L_{C}=6.6 \mathrm{~mm}\right)$ results in a generating a single passband response whose $3-\mathrm{dB}$ bandwidth extends over the span of the UWB frequency range.

\section{b) Notched-Band Implementation}

A wide notched-band was implemented in the UWB BPF by introducing asymmetry in the interdigital coupled lines. This is achieved by making the inner coupling line longer by folding it and extending the line to partially couple with U-shaped structure, as shown in Fig. 3. The results discussed below show the length of the extended coupled line determines the center frequency and 3$\mathrm{dB}$ bandwidth of the notch, and the position of the folded sections also has bearing on the notch's center frequency. The notch was centered at around $5.5 \mathrm{GHz}$ to blocking interference from WLAN signals. In order to enhance the filter's selectivity the U-shaped resonator was loaded with a T-shaped open-circuited stub that generates two additional resonant modes and transmission zeros (TZ) which were strategically located at the lower and upper cut-off frequencies.

It's discernible from the simulation analysis in Fig. 4(a) that as the length of the inner coupled line extension $\left(L_{m}\right)$ is increased slightly from 1 to $1.5 \mathrm{~mm}$ results in the center frequency of the notchedband to decrease from 5.58 to $5.19 \mathrm{GHz}$, and its $3-\mathrm{dB}$ bandwidth to increase from 0.3 to $0.55 \mathrm{GHz}$. 
The position of the folded coupled line $\left(d_{m}\right)$ too controls the center of the notched-band as shown in Fig. 4(b). In fact an increase in $d_{m}$ from 1 to $2 \mathrm{~mm}$ shifts the center frequency upwards from $5.59 \mathrm{GHz}$ to $5.78 \mathrm{GHz}$. The width of the fold $\left(W_{m}\right)$ also affects the location of the notched-band to a lesser extent. When $W_{m}$ is varied from 0.1 to $0.3 \mathrm{~mm}$, the center frequency of the notched-band decreases from 5.67 to $5.55 \mathrm{GHz}$, as shown in Fig. 4(c). The proposed asymmetric coupling structure provides three parameters of the coupled line that can be used to finely tune the center frequency and 3-dB bandwidth of the notched-band.

\section{c) Selectivity Improvement}

Filter selectivity is important as it determines the degree to which the filter suppresses the effects from noise and interference. To increase the selectivity in the proposed UWB BPF it was necessary to introduce two additional resonant modes in the filter's passband and two transmission zeros which were located at upper and lower cut-off frequencies. This was achieved by loading the U-shaped resonator with a T-shaped open-circuited stub, as shown in Fig. 5(a).

The resonance characteristics of U-shaped MMR loaded with the T-shaped stub as a function of stub parameters $\mathrm{L}_{\mathrm{T}}$ and $\mathrm{W}_{\mathrm{T}}$ is shown in Fig. 5(b). When $\mathrm{L}_{\mathrm{T}}$ is increased from 0 to $3.5 \mathrm{~mm}$, the two resonate modes $\left(f_{T 1}\right.$ and $\left.f_{T 2}\right)$ and the two TZs $\left(f_{Z 1}\right.$ and $\left.f_{Z 2}\right)$ distinctly move to lower frequency as shown in Fig. 5(b). This also applies by varying $W_{T}$. The frequency of the resonance modes and the two transmission zeros were thus strategically located at the upper and lower cut-off frequencies to sharpen the rejection skirts. As the T-shaped stub is loaded at the center of U-shaped MMR, it has no affect on odd modes, i.e. $f_{m 1-o d d}$ and $f_{m 3-o d d}$, however it slightly effects $f_{m 2-e v e n}$.

\section{Optimized MMR Structure and Measurement Results}

The MMR structure with five resonant modes $\left(f_{T 1}, f_{m 1-o d d}, f_{m 2-e v e n}, f_{m 3-o d d}, f_{T 2}\right)$ and two TZs $\left(f_{z 1}, f_{z 2}\right)$ enables a highly selective UWB filter. The inclusion of asymmetry in the coupling lines between the $50 \Omega$ input/output feed-lines and the MMR provides a notched-band necessary to mitigate interference with WLAN signals. The final configuration of the proposed filter is shown in Fig. 6 where the T-shaped stub is modified to occupy less space and make overall circuit size more compact. Input/output feed-lines are rotated by 90 degrees and its corners chamfered to reduce reflection. The coupling with the MMR was enhanced by introducing a dielectric slot in the ground-plane which is located under the coupling-lines.

Agilent ADS Momentum was used to optimize the proposed filter. The final dimensions are: $L_{1}=$ 2.7, $W_{1}=0.3, L_{2}=8, W_{2}=0.25, L_{T 1}=1, L_{T 2}=1.6, L_{T 3}=0.85, L_{T}=3.75, W_{T}=0.25, L_{p}=0.45, L_{m 1}$ $=1.25, L_{m 2}=1.75, W_{m}=0.2, d_{m}=2.1, L_{C}=7.1, L_{A}=4.9, W_{A}=1.3, W_{0}=1, a=2.1, b=1, c=$ 0.25 , strip_ $w=0.1$, and gap_w $=0.1$. All units are in millimeters. The slot allows the realizable gap between the coupling lines. From a practical point of view another feature of this structure is the absence any short-circuits, which is the case for stubs reported in [14][15][19]. The proposed filter is simpler and therefore cheaper to fabricate. Proposed filter was constructed on the Rogers RO4003 substrate with relative dielectric constant: $\varepsilon_{r}=3.38$, thickness: $h=0.508 \mathrm{~mm}$ and $\tan \delta=0.0022$. The circuit size of the filter is $9.4 \mathrm{~mm} \times 9.9 \mathrm{~mm}$ or $0.35 \lambda_{g} \times 0.37 \lambda_{g}$. Photographs of the fabricated notched-band UWB BPF are shown in Fig. 7.

The performance of the filter was measured using Agilent E5071C Network Analyzer. Fig. 8 shows the simulation and measurement S-parameter results of the proposed filter. There is generally good agreement between simulation and measurement results, and any discrepancy is attributed to manufacturing tolerance and non-precise SMA connection.

It can be seen in Fig. 8(a), the simulated 3-dB passband is between 3.15 and $10.47 \mathrm{GHz}$, i.e. a bandwidth of $7.32 \mathrm{GHz}$ which is centered at $6.81 \mathrm{GHz}$, The fractional bandwidth (FBW) is $107.49 \%$, which is in good agreement with ideal UWB BPF specification. The filter exhibits sharp passband selectivity with TZs placed near the edge of the passband at 2.98 and $10.84 \mathrm{GHz}$. The corresponding passband edge measured is at 3.08 and $12.35 \mathrm{GHz}$. The skirt factor (S.F.) is used to evaluate the selectivity of the filter which is defined as fraction of 3-dB bandwidth to $30-\mathrm{dB}$ bandwidth of the passband [6]. The S.F. of the proposed filter is 0.942 , which is very good and much better than the notched-band filters reported in [8]-[21]. The simulation shows a notched-band between 5.14 and 5.84 
$\mathrm{GHz}$, with a rejection level of $48.33 \mathrm{~dB}$ centered at $5.49 \mathrm{GHz}$, and 3-dB FBW of $12.75 \%$. The measured notched-band is between 5.04 and $5.79 \mathrm{GHz}$ with a rejection level of $36.27 \mathrm{~dB}$ centered at $5.42 \mathrm{GHz}$, and $3-\mathrm{dB}$ FBW of $13.85 \%$. The agreement between the simulation and measurement results on the notched-band is excellent. The measured results confirm the proposed UWB filter is capable of suppressing WLAN bands, i.e. 5.2 and $5.8 \mathrm{GHz}$ from 5.15 to $5.825 \mathrm{GHz}$. The filter's group delay, shown in Fig. 8(b), has good linearity across the UWB passband. A comparison is provided in Table 1 of the key features of the proposed filter with reported other notched-band UWB filters.

\section{Conclusion}

It was shown that a U-shaped open-circuited structure that is capacitively coupled to the input/output feed-lines with high impedance microstrip lines generates multiple resonant modes. By increasing the coupling between the coupled lines the structure can be transformed into an UWB filter. By introducing asymmetry in the coupling line results in the creation of a notched-band with high rejection level inside the passband of the filter, and whose bandwidth and center frequency can be controlled by simply manipulating the dimensions of one of coupled lines. The notched-band was located to mitigate the interference from WLAN systems. The selectivity of the filter was improved by introducing two additional resonant modes within the passband and transmission zeros at the filters upper and lower band edge. The resulting UWB bandpass filter is compact in size and exhibits high selectivity and a wide notched-band with a high rejection level as well as a wide out-of-band rejection.

\section{References}

[1] "FCC, Revision of Part 15 of the Commission's Rules Regarding Ultra-Wideband Transmission System," Washington, DC, ET- Docket 98-153, Feb. 2002.

[2] L. Zhu, S. Sun, and W. Menzel, "Ultra-Wideband (UWB) Bandpass Filters using Multiple-Mode Resonator," IEEE Microw. Wireless Compon. Lett., vol. 15, no. 11, pp. 796-798, Nov. 2005.

[3] S. S. Gao, X. S. Yang, J. P. Wang, S. Q. Xiao \& B. Z. Wang, "Compact Ultra-Wideband (UWB) Bandpass Filter Using Modified Stepped Impedance Resonator," J. of Electromagn. Waves and Appl., vol. 22, pp. 541-548, 2008.

[4] S. W. Wong, and L. Zhu, "Quadruple-Mode UWB Bandpass Filter With Improved Out-of-Band Rejection," IEEE Microw. Wireless Compon. Lett., vol. 19, no. 3, pp. 152 - 154, Mar. 2009.

[5] Q. X. Chu, and X. K. Tian, "Design of UWB Bandpass Filter Using Stepped-Impedance Stub-Loaded Resonator," IEEE Microw. Wireless Compon. Lett., vol. 20, no. 9, pp. 501-503, Sept. 2010.

[6] Q.-X. Chu, X.-H. Wu, and X.-K. Tian, "Novel UWB Bandpass Filter Using Stub-Loaded Multiple-Mode Resonator," IEEE Microw. Wireless Compon. Lett., vol. 21, no. 8, pp. 403-405, Aug. 2011.

[7] Z. Shang, X. Guo,B. Cao, B. Wei, X. Zhang, Y. Heng, G. Suo, and X. Song, "Design of a Superconducting UltraWideband (UWB) Bandpass Filter With Sharp Rejection Skirts and Miniaturized Size," IEEE Microw. Wireless Compon. Lett., vol. 23, no. 2, pp. 72-74, Feb. 2013.

[8] H. Shaman, and J.-S. Hong, "Asymmetric Parallel-Coupled Lines for Notch Implementation in UWB Filters," IEEE Microw. Wireless Compon. Lett., vol. 17, no. 7, pp. 516-518, Jul. 2007.

[9] S. W. Wong, and L. Zhu, "Implementation of Compact UWB Bandpass Filter With a Notch-Band," IEEE Microw. Wireless Compon. Lett., vol. 18, no. 1, pp. 10-12, Jan. 2008.

[10] C.-H. Lee a, I-C. Wang b, and L.-Y. Chen, "MMR-based Band-Notched UWB Bandpass Filter Design," J. of Electromagn. Waves and Appl., vol. 22, pp. 2407-2415, 2008.

[11] F. Wei, L. Chen, Q.-Y. Wu, X.-W. Shi, and C.-J. Gao, "Compact UWB Bandpass Filter with Narrow Notch-Band and Wide Stop-Band," J. of Electromagn. Waves and Appl., vol. 24, pp. 911-920, 2010.

[12] C. H. Kim, and K. Chang, "Ultra-Wideband (UWB) Ring Resonator Bandpass Filter With a Notched Band," IEEE Microw. Wireless Compon. Lett., vol. 21, no. 4, pp. 206-208, Apr. 2011.

[13] H. Chu, X. Q. Shi, and Y. X. Guo, "Ultra-Wideband Bandpass Filter with a Notch Band Using EBG Array Etched Ground," J. of Electromagn. Waves and Appl., vol. 25, pp. 203-209, 2011.

[14] H. Chu, and X. Q. Shi, "Compact Ultra-Wideband Bandpass Filter Based on SIW and DGS Technology with a Notch Band," J. of Electromagn. Waves and Appl., vol. 25, pp. 589-596, 2011.

[15] H. Zhu, Q.-X. Chu, and X.-K. Tian, "Compact UWB Bandpass Filter using Folded-T-shaped Resonator with a Notch-Band," J. of Electromagn. Waves and Appl., vol. 26, no. 10, pp. 1366-1373, Jul. 2012.

[16] J. Xu, W. Wu, W. Kang, and C. Miao, "Compact UWB Bandpass Filter with a Notched Band Using Radial Stub Loaded Resonator," IEEE Microw. Wireless Compon. Lett., vol. 22, no. 7, pp. 351-353, Jul. 2012.

[17] M. A. Honarvar and R. A. Sadeghzadeh, "Design of Coplanar Waveguide Ultrawideband Bandpass Filter Using Stub-Loaded Resonator with Notched Band," Microwave Opt. Technol. Lett., vol. 54, no. 9, pp. 2056-2061, Sep. 
2012.

[18] H. Zhu, and Q.-X. Chu, "Ultra-Wideband Bandpass Filter With a Notch-Band Using Stub-Loaded Ring Resonator," IEEE Microw. Wireless Compon. Lett., vol. 23, no. 7, pp. 341-343, Jul. 2013.

[19] J. Xu , C. Miao, G. Yang, L. Cui , J.-D. Zhang, Y.-X. Ji, and W. Wu, "Compact and Sharp Rejection Microstrip UWB BPF with Dual Narrow Notched Bands," J. of Electromagn. Waves and Appl., vol. 25, pp. 2464-2473, 2011.

[20] J. Q. Liu , K. J. Song, and Y. Fan, "UWB BPF with Triple Notched Bands Using Novel Dual-Mode SIR and Asymmetrical Coupling Structure," J. of Electromagn. Waves and Appl., vol. 26, no. 16, pp. 2112-2120, Nov. 2012.

[21] M. Mirzaee, "A Novel Compact UWB BPF with Independently Controllable Double Notched Bands and Super Wide Upper Stopband," J. of Electromagn. Waves and Appl., vol. 27, no. 1, pp. 77-86, 2013. 


\section{Figures}

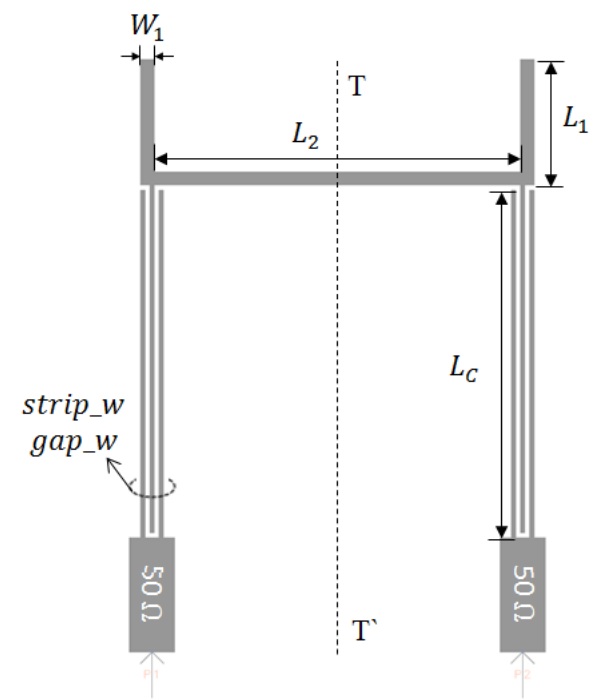

(a)

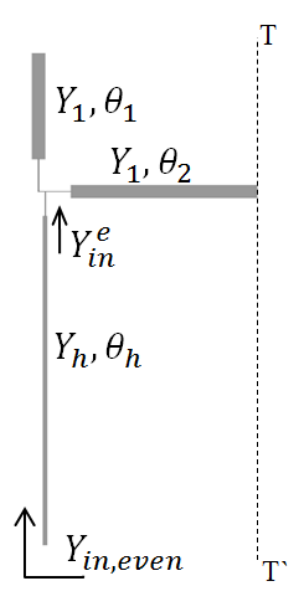

(b)

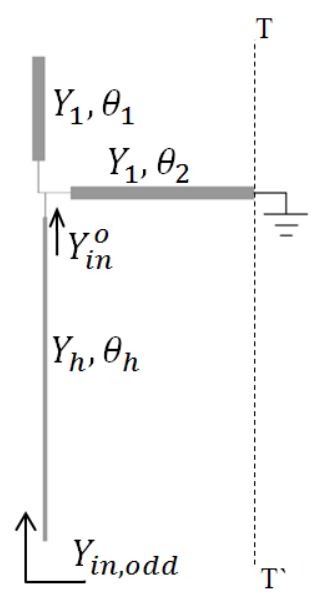

(c)

Figure 1: (a) Initial multimode microstrip structure, (b) equivalent even-mode circiut, and (c) equivalent odd-mode circiut.

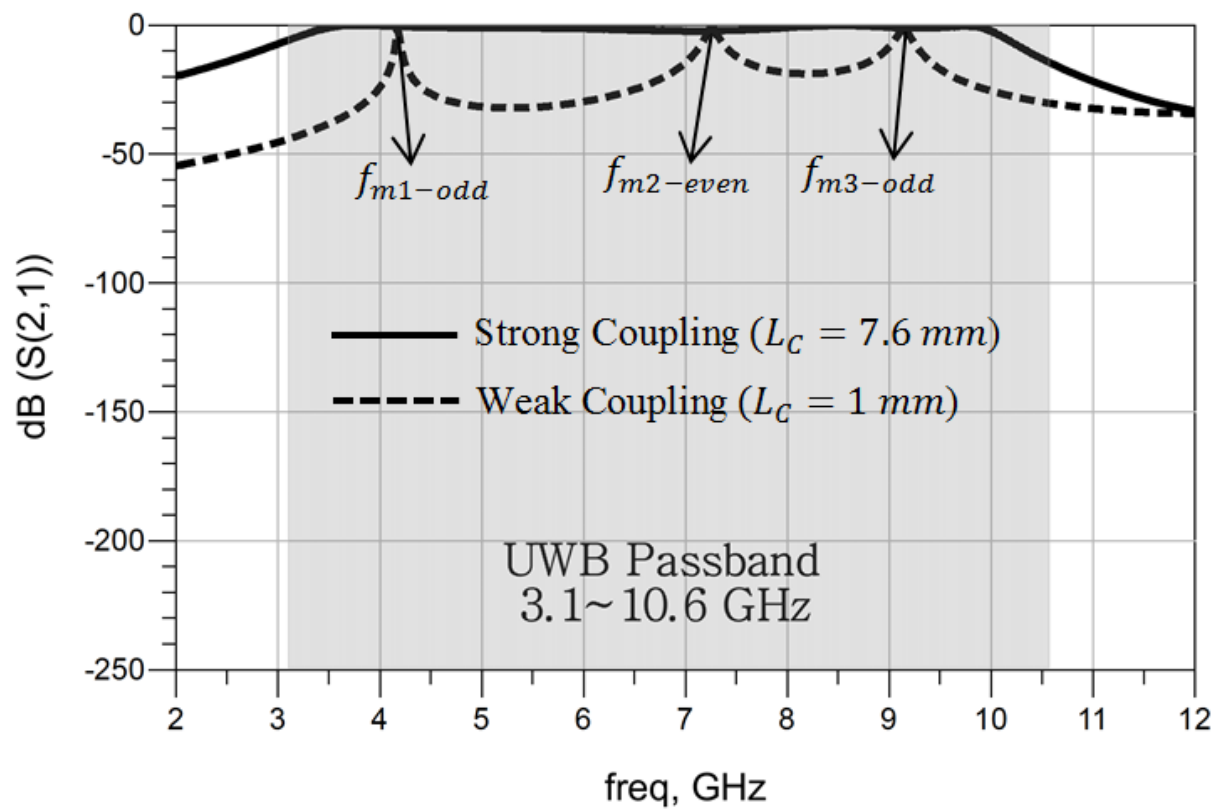

Figure

2: $\quad$ Simulated

-magnitude

of

the

initial

MMR

in

Figure 1(a) under weak and strong coupling. The assosiated dimensions are: 




Figure 3: Modified filter in

Figure 1(a) to produce a wide notched-band.



(a)



(b)

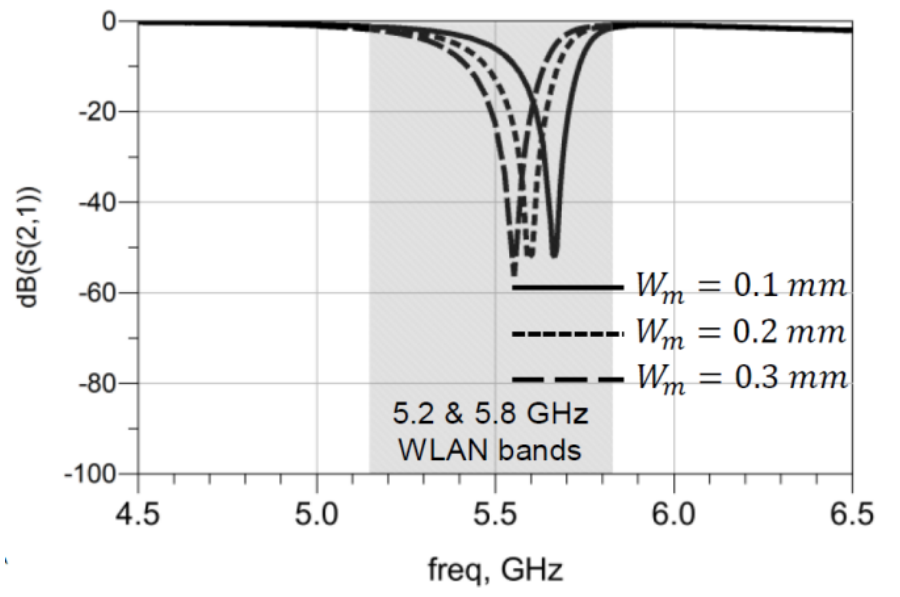

(c)

Figure 4: Effect on the notched-band by: (a) the length of the arm ( ) and open circuited stub load, (b) the position of the $\operatorname{arm}(\quad)$, and (c) the width of the arm ( ). 


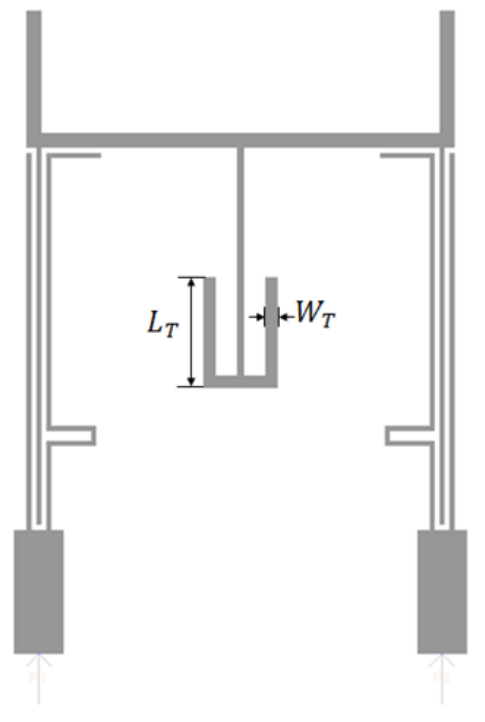

(a)

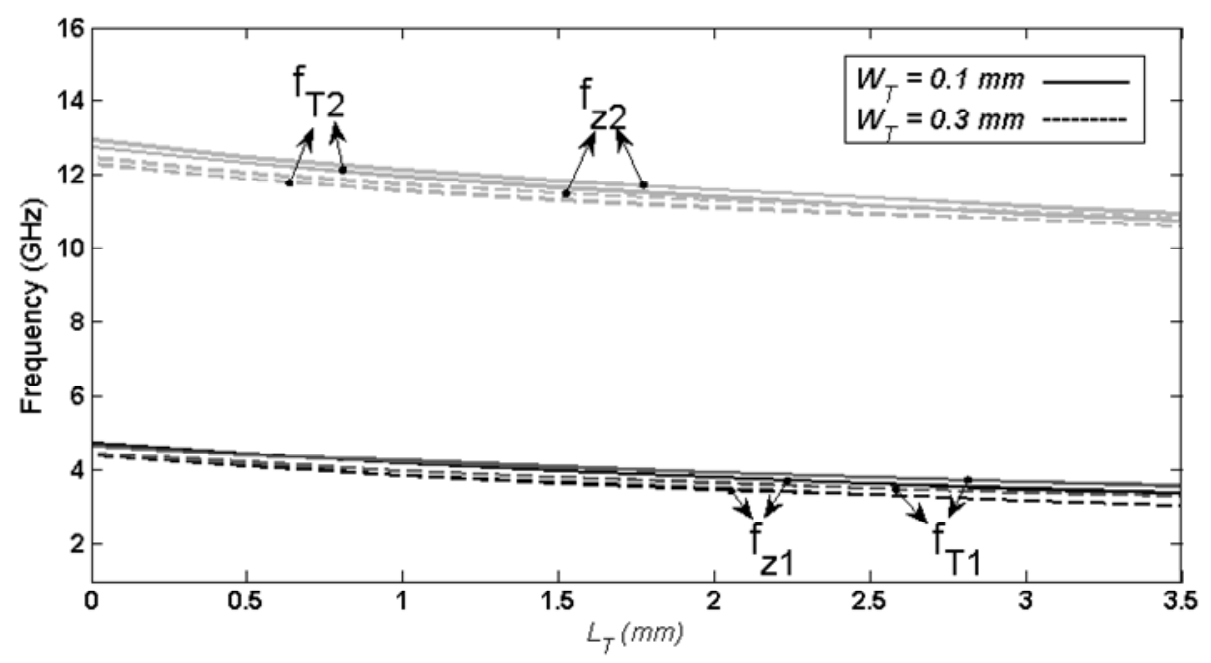

(b)

Figure 5: (a) T-shaped stub loading on the U-shaped resonator to increase the filter's selectivity, and (b) effect of the Tshaped stub on resonant modes and transmission zeros.

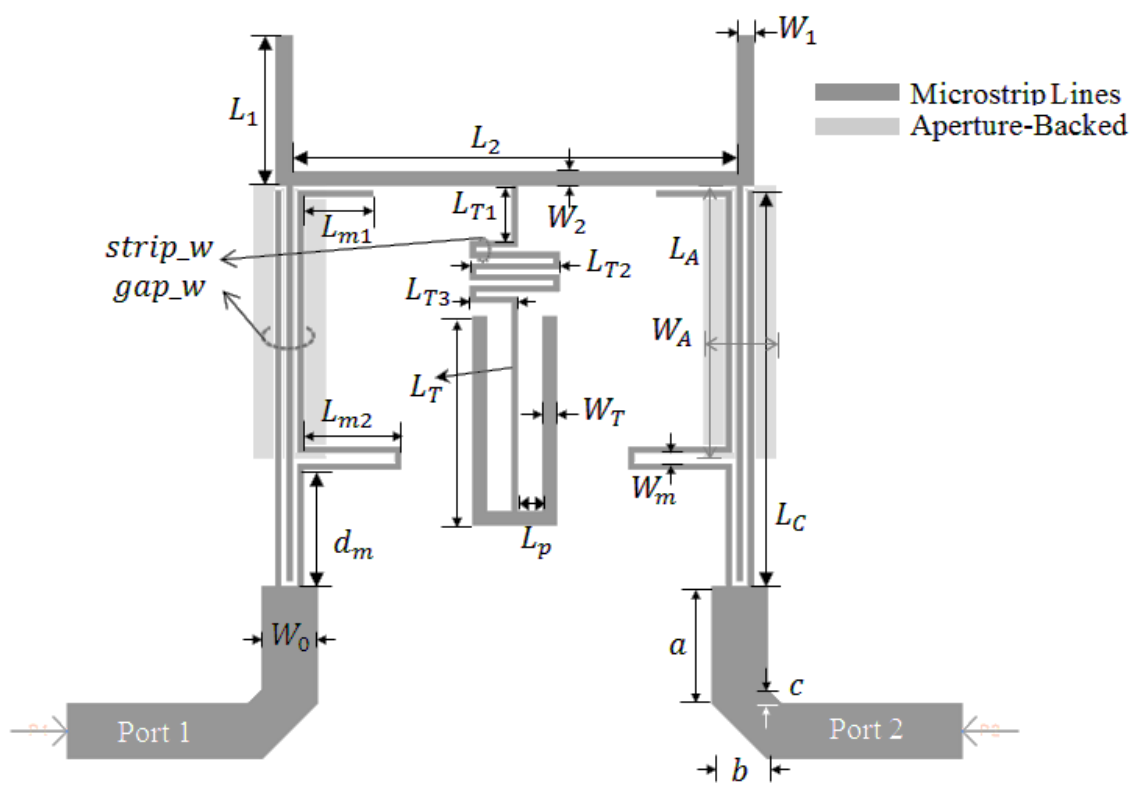

Figure 6: Final configuration of the proposed UWB filter.
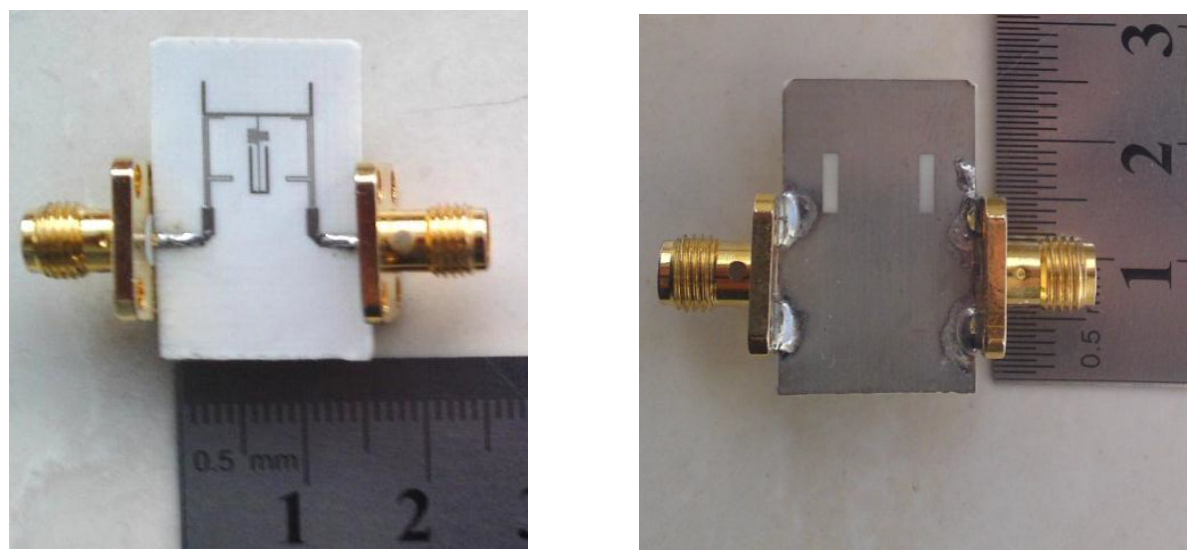
Figure 7: Fabricated notched-band UWB BPF, (a) top view, and (b) bottom view.

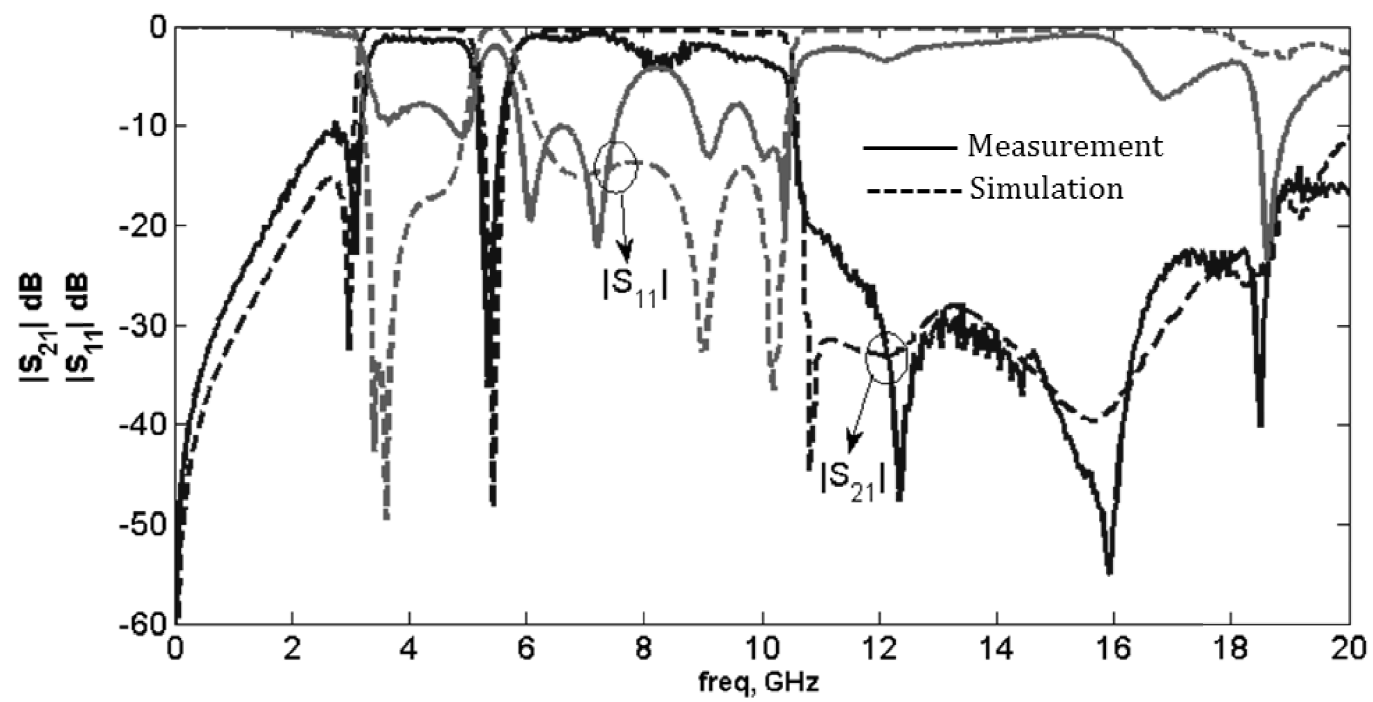

(a)

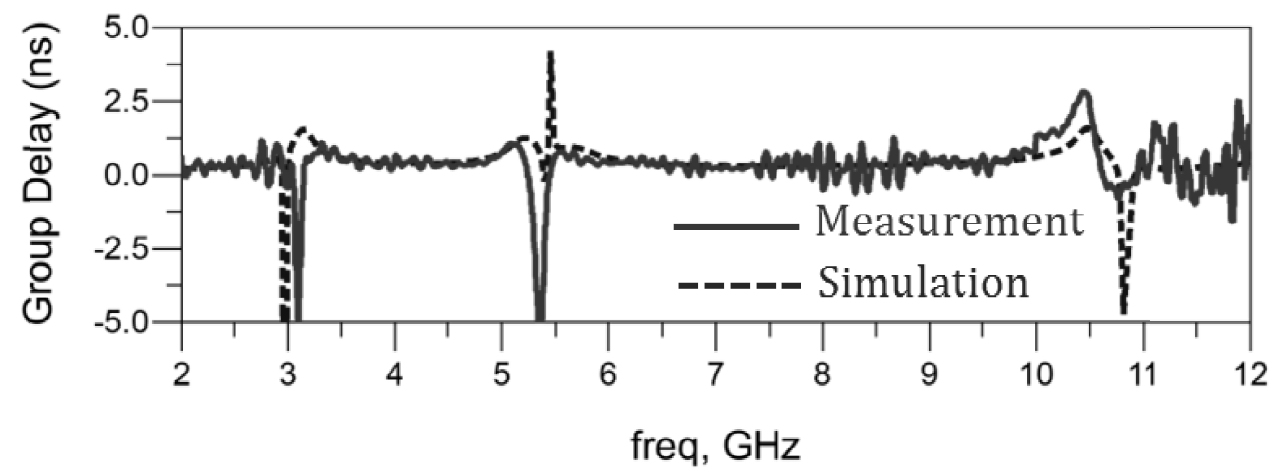

(b)

Figure 8: Simulation and measurement S-parameters, (a) and and (b) Group delay.

\section{Table}

Table 1: Comparison of this work with other notched-band UWB filters.

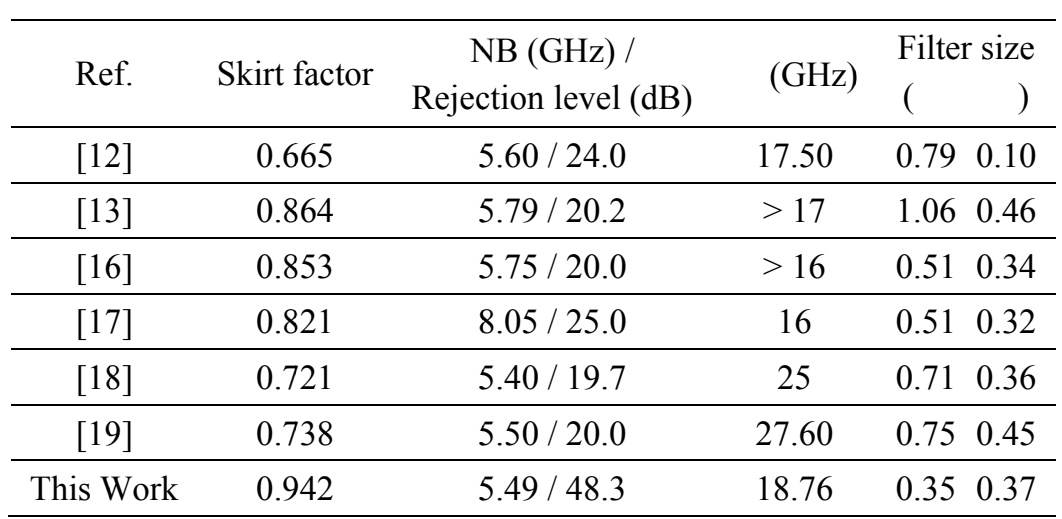

NB: notched-band center frequency; : upper stopband defined at $20 \mathrm{~dB}$ attenuation 